\title{
Computation of convective heat transfer coefficient for finite inclined and isothermal plate
}

\author{
M. Bouksani*, M. N. Bouaziz** \\ *Department of Drilling and Mechanic of Petroleum fields, University Kasdi Merbah, BP 511 Route Ghardaïa, Ouargla \\ 30 000, Algeria, E-mail: mouhov2003@yahoo.fr \\ **Biomaterials and Transport Phenomena Laboratory, University Yahia Fares, Medea 26000, Algeria, \\ E-mail:mn_bouaziz@email.com
}

cross $^{\text {ref }}$ http://dx.doi.org/10.5755/j01.mech.23.4.14709

\section{Nomenclature}

$B_{0}$ - magnetic flux density, $\mathrm{Wb} / \mathrm{m}^{2} ; C_{p}$ - specific heatat constant pressure, $\mathrm{J} / \mathrm{kg}{ }^{\circ} \mathrm{C} ; f$ - Reduced stream function defined by Eq. $9 ; E c$-Eckert number; $g$-gravitational acceleration, $\mathrm{m} / \mathrm{s}^{2} ; G r_{x}$ - Grashof number, $G r_{x}=\frac{g \beta \Delta T x^{3}}{v^{2}}$; $L$ - plate length, m; $M$ - dimensionless magnetic parameter; $N u_{x}$ - local Nusselt number, $N u_{x}=\frac{h x}{\lambda} ; P$ - Pressure, Pa; $\operatorname{Pr}$ - Prandtl number, $\operatorname{Pr}=\frac{v}{\alpha} ; \quad R a_{x}$ - Rayleigh number $R a_{x}=\frac{g \beta \Delta T x^{3}}{v \alpha} ; T$-temperature, ${ }^{\circ} \mathrm{C} ; U_{c}$ - characteristic velocity; $u, v$-direction velocity, $\mathrm{m} / \mathrm{s} ; x, y$-axial, normal coordinates

greek symbols -

$\alpha$-effective thermal diffusivity, $\mathrm{m}^{2} / \mathrm{s} ; \beta$-coefficient of thermal expansion, ${ }^{\circ} \mathrm{C}^{-1} ; \delta_{T}$ - thermal boundary layer thickness, $\mathrm{m}$; $\theta$-dimensionless temperature defined in Eq. 9; $\eta$-similarity variable; $v$-kinematics viscosity, $\mathrm{m} / \mathrm{s}^{2}$; $\xi$ - nonsimilar parameter defined by Eq. $13 ; \rho$ - fluid density, $\mathrm{kg} / \mathrm{m}^{3} ; \sigma$-fluid electrical conductivity, $\mathrm{A} / \mathrm{V} \mathrm{m}$; $\varphi$ - angle inclination, ${ }^{\circ} ; \psi$ - stream function, $\mathrm{m}^{2} / \mathrm{s}$ )

superscripts -

' - differentiation with respect to $\eta$

subscripts -

$\infty$ - conditions far away from the surface; $\mathrm{w}$ - Wall surface; I,II - region I or II; $x$ - local; $d$ - global

\section{Introduction}

The study of the relatively new flow problems which involve the interaction of several phenomena has a wide range of application in the field of science and technology. For example, the presence of a magnetic field with dissipation effects in these flows is often encountered. It finds many applications in the systems of renewable energy or in food processing where plates of finite dimensions with arbitrary inclination emitted the heat flux transfer. Some works have been conducted in this area and focused on the inclined plates [1-8].

The studies of the natural convection under the influence of a magnetic field adjacent to a semi-infinite plate were investigated extensively [9-18]. More realistic plate expressed with finite dimensions has received little atten- tion, compared with the idealized or semi-infinite plates. Great discrepancies are observed between the experimental results and the theoretical calculations based on the concept of semi-infinite boundary layers, fig.1.In the laminar range, more than $45 \%$ of error is found for inclined plates, as reported by Lewandowski and Radziemska [19].

Furthermore and without succeeding, tentative attempts are carried out to reduce the differences observed, by increasing accuracy or by defining simplified assumptions more accurately. The right way is rather to attribute these differences to the inappropriate physical model and the research of a new model becomes obvious. Based on some simplifications, quasi-analytical solution was developed in Lewandowski [20]. Gosh and Pop [21] present a new approach for the finite dimensions rotating plates taking into account the MHD natural convection.

The physical and classical model of convective heat transfer with or without magnetic field was proposed by Schmidt and Beckmann; it was obtained on a basis of experimental results of visualization of the boundary thermal layer on a vertical isothermal plate (Fig. 1,a). The same model has been also adopted for a description of the results obtained with inclined (Fig. 1,b) and horizontal (Fig. 1, c) plates. This similar model has also been based on a homogeneous boundary layer, increasing on a semiinfinite flat surface and which is similar to the forced convection in the boundary layer shape. Fig. 1 presents a graphical interpretation of this model.

For plate with finite dimensions, two boundary layers are developed naturally from the two leading edges. This really and physically flow is corroborated with experimental investigations.

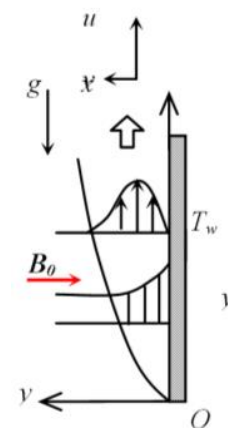

a

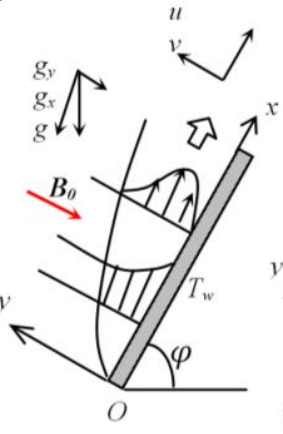

b

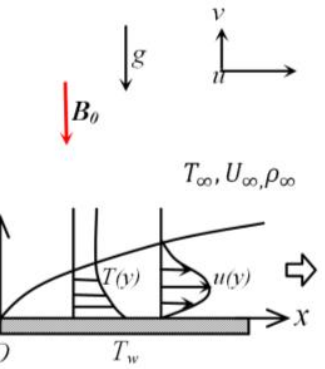

c
Fig. 1 Classical Model of free convection heat transfer from vertical (a), inclined (b) and horizontal (c) plate, (Schmidt and Beckmann [22]) 
In order to obtain a basic insight into the flows over slightly inclined plates, Kimura et al.[23] carried out flow visualizations using dye with a 50 -mm-wide test plate and heating fluxes were $q=1000 \mathrm{~W} / \mathrm{m}^{2}$, and the Rayleigh number was kept constant as $R a=6 \times 10^{7}$ and the representative results are shown in Fig. 2. To make the flow visible, Uranin was utilized as a dye marker, and the dye was released slowly from the slits flush-mounted on both leading edges of the plate. The photographs were taken from the side of the test plate by varying the inclination angle from $\varphi=0$ (horizontal) to $15^{\circ}$ at $5^{\circ}$ intervals.
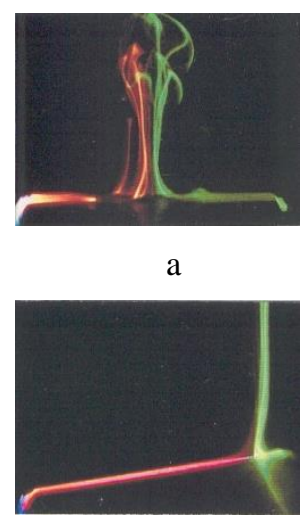

C

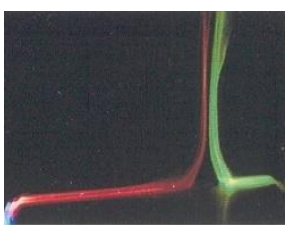

b

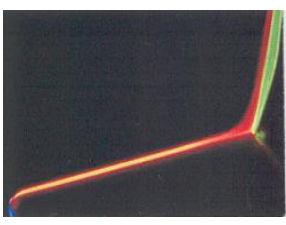

d
Fig. 2 Visual photographs of free convection heat transfer from an inclined isothermal finite plate: $\mathrm{a}-\varphi=0^{\circ}$; $\mathrm{b}-\varphi=5^{\circ} ; \mathrm{c}-\varphi=10 ; \mathrm{d}-\varphi=15^{\circ}$ (Kimura et al. [23])

Then, the appropriate model shows two separate and distinguished regions with different fluid motions. In the suggested model (Fig. 3), the transition from one case to other proceeds together with the displacement of the separation point. Thus, the case of the inclined plate is virtually a general model concerning plate arbitrary oriented in unlimited space (Fig. 3.(b)) in which vertical (Fig. 3.(a)) and horizontal (Fig. 3.(c)) positions of plates constitute only specific cases. In the first region, the direction of fluid flow inside the boundary layer and parallel to the plate buoyancy force component converge, while in the second one these directions are opposite.

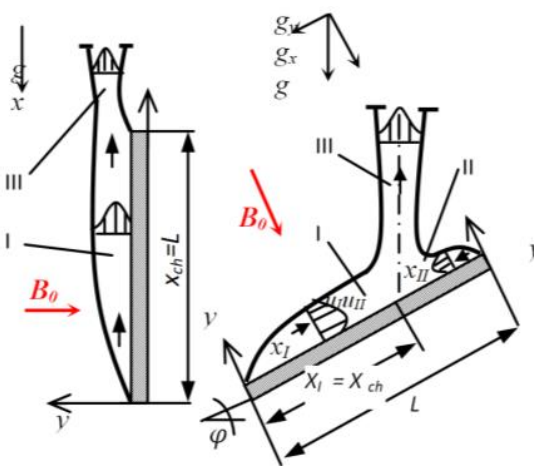

a

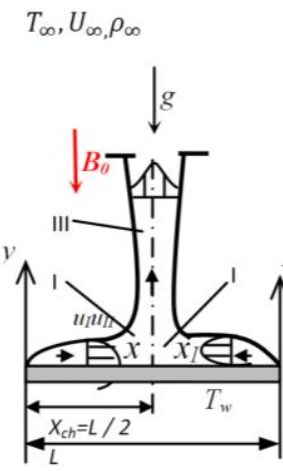

C
Fig. 3 Realistic model of free convection for vertical (a), inclined (b) and horizontal (c) plate

According to this pattern model, the streamlines are radial, and fluid flows toward a point at the centre of the plate where the boundary layer transforms into a plume. The versatility of the suggested model consist of the fact that a change in surface inclination angle results in fluent changes of the participation of regions I and II in the heat exchange, whereas participation of region III remains constant. For the vertical plate, the differences between regions I and II gradually disappear. In the final effect of horizontal plates, two symmetrical boundary layers exist, growing from each edge (region I = region II) and transforming at the separation point into free stream heat convection (plume).On the other hand, in the case of vertical plate the model is identical to the hitherto applied one, because then only one boundary layer appears (region $\mathrm{II}=0$ ) subsequently converting into a wake and next into a plume (region III).

To our knowledge, exclusive investigation of Gosh and Pop [21], this problem rose above, has not received any attention in the literature. All works have been published and devoted to MHD free convection flows are based on the Schmidt and Beckmann model, which the semi-infinite concept is applied.

Owing to the visualization of the two boundary layers, the purpose of this paper is to highlight some numerical results for MHD natural convection over isothermal and an inclined plate of finite dimensions and taking into account the magnetic dissipation.

\section{Mathematical analysis}

Using the proposed general model as it is shown in (Fig. 3, b), which encompasses all angles inclination, and as discussed previously, we assume that due to the inclination of the plate, the boundary layer behavior permit to obtain two main flow (regions I and II), one frame at each leading edge.

We consider the steady, laminar, MHD free convection flow from a finite flat plate of length $L$, which is inclined with an angle $\varphi$ from the horizontal. With $x$ coordinate is measured from the leading of each edge of the plate and the coordinate is measured normally from the plate to the fluid, the gravitational acceleration $g$ is acting downward and a magnetic field of uniform strength $B_{0}$ is applied in the y direction which is normal to the flow direction. Further, the fluid is assumed to be Newtonian and electrically conducting. The temperature of the surface is held uniform $T_{w}$ which is higher than the ambient temperature $T_{\infty}$. The thermo-physical properties of the fluid are assumed to be constant except for the density variation that induces the buoyancy force.

With this assumption and the application of the Oberbeck-Boussinesq approximation, the governing conservation equations for laminar boundary layer free convection flow can be written as:

$$
\frac{\partial u}{\partial x}+\frac{\partial v}{\partial y}=0
$$

$$
\begin{aligned}
& u \frac{\partial u}{\partial x}+v \frac{\partial v}{\partial y}=v \frac{\partial^{2} u}{\partial y^{2}}-\frac{1}{\rho} \frac{\partial P}{\partial x} \pm \\
& \pm g \beta\left(T-T_{\infty}\right) \sin \varphi-\frac{\sigma B_{0}^{2}}{\rho} u ;
\end{aligned}
$$




$$
\begin{aligned}
& 0=-\frac{1}{\rho} \frac{\partial P}{\partial y}+g \beta\left(T-T_{\infty}\right) \cos \varphi ; \\
& u \frac{\partial T}{\partial x}+v \frac{\partial T}{\partial y}=\alpha \frac{\partial^{2} T}{\partial y^{2}}+\frac{\sigma B_{0}^{2}}{\rho c_{p}} u^{2},
\end{aligned}
$$

where \pm signs are for region I and region II, respectively; $\beta$ is the coefficient of thermal expansion; $\sigma$ is the electrical conductivity $; v$ is the kinematic viscosity; $\alpha$ is the thermal diffusivity and $C_{p}$ is the specific heat capacity of the fluid, and $\rho$ is the density of the fluid.

It must be pointed out, however, that $P$ is the static pressure difference induced by the buoyancy force (i.e. $P=0$ outside the boundary layer). The $x$-momentum and $y$-momentum equations, Eq. (2) and Eq. (3), can be combined with integration for finding the buoyancy induced streamwise pressure gradient from the Eq. (3) as:

$$
-\frac{1}{\rho} \frac{\partial P}{\partial x}=g \beta \cos \varphi \frac{\partial}{\partial x} \int_{y}^{\delta}\left(T-T_{\infty}\right) d y
$$

This leads to use only the transformed Eq. (2):

$$
\begin{aligned}
& u \frac{\partial u}{\partial x}+v \frac{\partial v}{\partial y}=v \frac{\partial^{2} u}{\partial y^{2}}+g \beta \cos \varphi \frac{\partial}{\partial x} \int_{y}^{\delta}\left(T-T_{\infty}\right) d y \pm \\
& \pm g \beta\left(T-T_{\infty}\right) \sin \varphi-\frac{\sigma B_{0}^{2}}{\rho} u .
\end{aligned}
$$

The boundary conditions are defined as follow:

$$
\begin{aligned}
& \text { At } y=0: u=0, v=0 \text { and } T=T_{w} \\
& \text { for } y \rightarrow \infty(\text { or }: y=\delta): u=0, v=0 \\
& \text { and } T \rightarrow T_{\infty} .
\end{aligned}
$$

It is noted here that Eq. (6) reduced to that for a vertical plate without the buoyancy-induced pressure gradient term when $\varphi=90^{\circ}$ and to that for a horizontal plate without the buoyancy force term when $\varphi=0^{\circ}$. Owing to the inclination of the plate, the boundary layer is not in the similarity form.

The system of Eq. (4), Eq. (6) and Eq. (7) will be transformed from $(x, y)$ coordinates to the dimensionless coordinates $\xi=\xi(x), \eta(x, y)$ by introducing the following transformations used by Chen [24] for $0^{\circ} \leq \varphi<90^{\circ}$ :

$$
\xi=\xi(x), \eta=\frac{y}{\xi(x)}=\frac{y}{x}\left(\frac{G r_{x} \times \cos \varphi}{5}\right)^{\frac{1}{5}}
$$

where $\xi$ depending only on $x$, is the non-similar parameter and $\eta$ is a pseudo-similarity variable and $G r_{x}$ is the local Grashof number defined as $G r_{x}=\frac{g \beta \Delta T x^{3}}{v^{2}}$. For a similar boundary layer, $\xi=0$ and $\eta$ reduces to a true similarity variable. One also introduces a reduced stream function $f(\xi, \eta)$ and a dimensionless temperature $\theta(\xi, \eta)$ defined as the same in Ref [24], respectively, such as:

$$
\left.\begin{array}{l}
f(\xi, \eta)=\frac{\psi(x, y)}{5 v\left(G r_{x} \times \cos \varphi / 5\right)^{\frac{1}{5}}} \\
\theta(\xi, \eta)=\frac{T-T_{\infty}}{T_{w}-T_{\infty}}
\end{array}\right\},
$$

where $\psi$ is the stream function which satisfies the continuity equation and is related to the velocity components in the usual way as $u=\frac{\partial \psi}{\partial y}$ and $v=-\frac{\partial \psi}{\partial x}$. Thus, the following equations are obtained:

$$
f^{\prime \prime \prime}+3 f f^{\prime \prime}-f^{\prime 2} \pm \xi \theta-M f^{\prime}+\frac{1}{5}\left[2 \eta \theta+2 \int_{\eta}^{\infty} \theta d \eta+3 \xi \int_{\eta}^{\infty} \frac{\partial \theta}{\partial \xi} d \eta\right]=3 \xi\left[f^{\prime} \frac{\partial f^{\prime}}{\partial \xi}-f^{\prime \prime} \frac{\partial f}{\partial \xi}\right]
$$

$$
\frac{1}{P r} \theta^{\prime \prime}+3 f \theta^{\prime}+5 M E_{c} f^{\prime 2}=3 \xi\left[f^{\prime} \frac{\partial \theta}{\partial \xi}-\theta^{\prime} \frac{\partial f}{\partial \xi}\right]
$$

with the boundary conditions:

$$
\left.\begin{array}{l}
f(\xi, 0)=f^{\prime}(\xi, 0)=f^{\prime}(\xi, \infty)=0 \\
\theta(\xi, 0)=1, \theta(\xi, \infty)=0
\end{array}\right\}
$$

In the foregoing equations, the primes denote partial differentiations with respect to $\eta, P r$ is the Prandtl number, $M$ is the magnetic parameter and $E_{c}$ is the Eckert number defined respectively as:

$$
\operatorname{Pr}=\frac{v}{\alpha} ; M=\frac{\sigma B_{0} L x^{2}}{\rho U_{c}\left(\frac{G r_{x} \times \cos \varphi}{5}\right)^{\frac{-1}{2}}} ; E_{c}=\frac{5 U_{c}^{2}(G r \cos \varphi)}{c_{p}\left(T_{w}-T_{\infty}\right) x^{2}},
$$

where: $U_{c}=\sqrt{g \beta \Delta T}$ and $\xi$ is found to have the following expression:

$$
\xi(x)=\left(\frac{G r_{x} \times \cos \varphi}{5}\right)^{\frac{1}{5}} \tan \varphi .
$$

This finding can be judiciously exploited to determine the velocity and the temperature profiles in the two regions. Eqs. (10-12) are valid for regions I and II with only difference in the signs.

As first approximation, we can delete the derivatives of $\xi$. Accurate solutions of the system can be checked with better approximation as prescribed in the two-level method.

$$
f^{\prime \prime \prime}+3 f f^{\prime \prime}-f^{\prime 2} \pm \xi \theta-M f^{\prime}+\frac{1}{5}\left[2 \eta \theta+2 \int_{\eta}^{\infty} \theta d \eta\right]=0
$$




$$
\frac{1}{\operatorname{Pr}} \theta^{\prime \prime}+3 f \theta^{\prime}+5 M E_{c} f^{\prime 2}=0
$$

\section{Results and discussion}

The set of Eq. (14) and Eq. (15), with the boundary conditions (12), which are valid for $0^{\circ} \leq \varphi<90^{\circ}$, have been solved numerically, first reduced to a system of firstorder differential equations which are then expressed in the finite-difference form and solved along with their boundary conditions by an iterative scheme. We can check the accuracy of the assumed missing initial condition, by comparing the calculated value of the different variables at the terminal point with the given value by the existence of the difference in improved values the missing initial conditions must be obtained.

It should be noted that the calculations are conducted for each region separately. Further, the separation point is estimated by the approximate result from the analytical procedure of Lewandowski [20] depending mainly on the angle of inclination. For any Rayleigh number, a least squares polynomial approximation is found as the

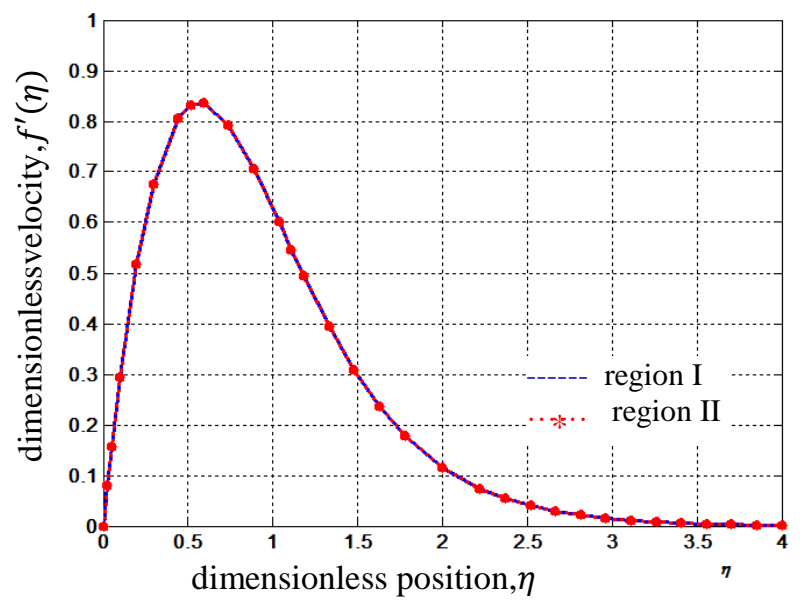

a best fitting up the four degree to represent the curve $\xi-\varphi$.

In order to gain physical insight, the velocity and temperature profiles against the dimensionless position $\eta$, for the both regions I and II, have been discussed by assigning numerical values to the parameter, encountered in the problem, i.e. numerical calculations were carried out for different values of angle inclination, Grashof number, Prandtl number, magnetic field parameter $M$, Eckert number $E_{c}$ and their effects on flow and heat transfer characteristics are analyzed graphically.

It note that, in order to shown and analyzed the difference between the two regions I and II, these curves are plotted together at the same time in Figs. 4-12.

Figs. $4, a, b-6, a, b$ depict the influence of inclination of the plate on the boundary layer of both regions I and II. Analysis of the visualization photographs gives evidence that for the horizontal surface $\left(\varphi=0^{\circ}\right)$, the boundary layers grow identically from opposite leading edges for that reason the Fig. 4, a, b shows confound in the velocity and temperature distribution for both region I and II.

It is seen in Fig. 5, a, b, that at increased inclination angle $\varphi$, the velocity profile in the first region grows

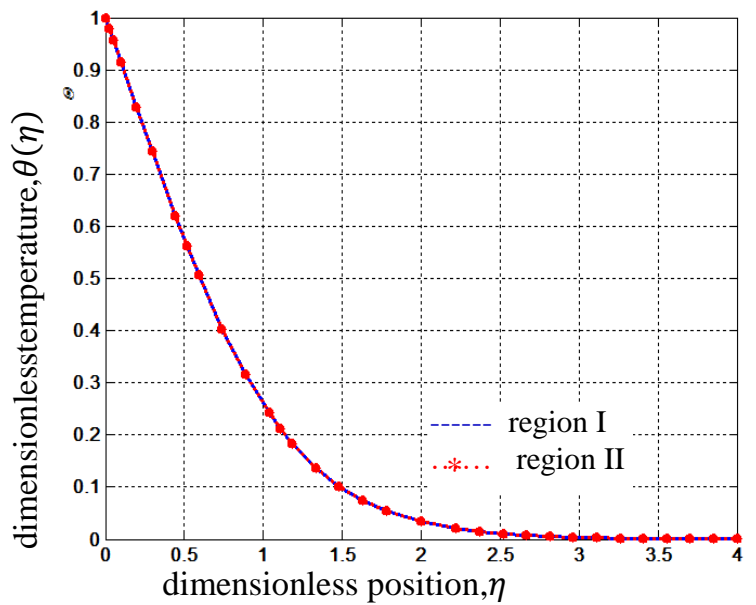

$\mathrm{b}$

Fig. 4 Velocity a) and temperature b) distributions against $\eta$ for horizontal plate $\left(\varphi=0^{\circ}\right), \operatorname{Pr}=0.72, G r=0.5^{*} 10^{3}$ and $M=0$

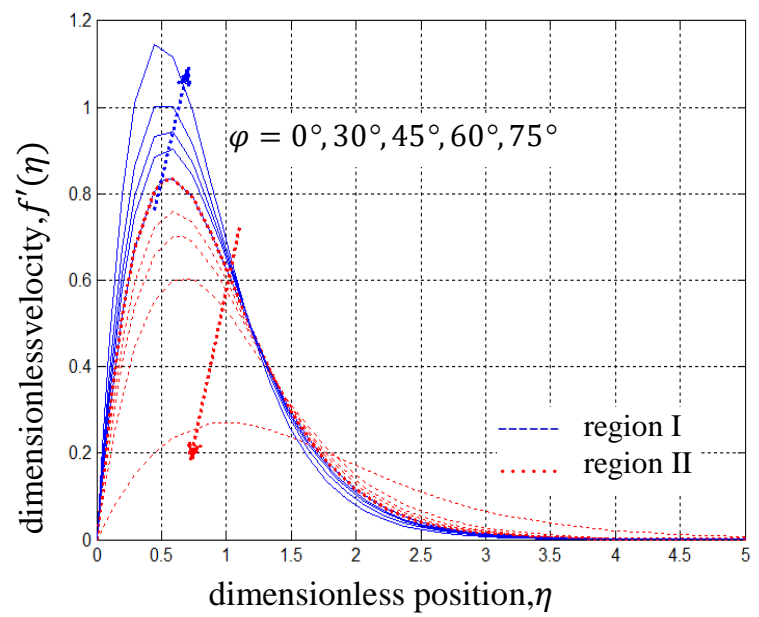

a

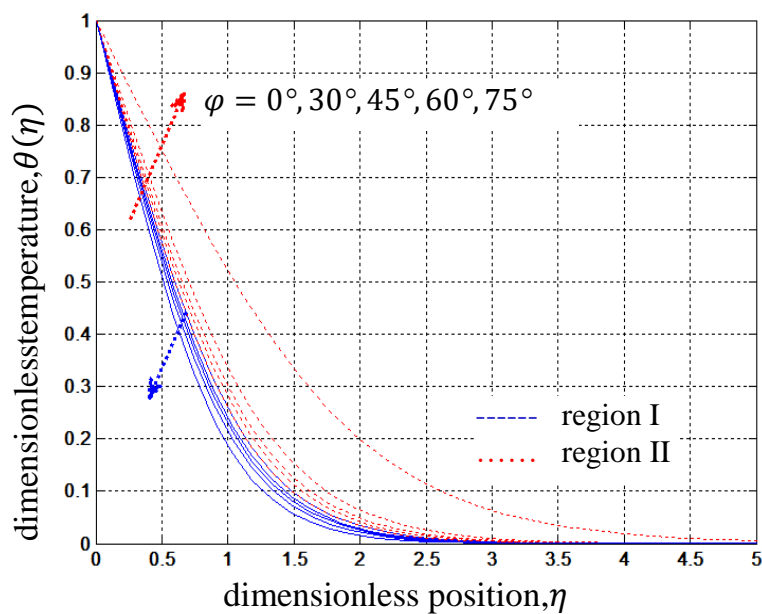

b

Fig. 5 Velocity a) and temperature b) distributions against $\eta$ for different inclination angle values, $P r=0.72$, $G r=0.5 * 10^{3}$ and $M=0$ 
more and more than the second region, which decrease more and more until that the velocity disappear because the separation point of boundary layers, through which passes the centerline, move to one (trailing) edge and the opposite boundary layers (identical for the horizontal case) begin to differ increasingly from each other. The influence of the angle of inclination on the fluid temperature shows that the thermal boundary layer decreases in the first region and increase in the second region with the increase of the angle of inclination of the plate.

In figures Fig. 6, a, b for inclination near to vertical $\left(\varphi=76.86^{\circ}\right)$, it is clear that just the first region exists which was dominating the free convection heat transfer flow because the second region was disappear. The veloci-

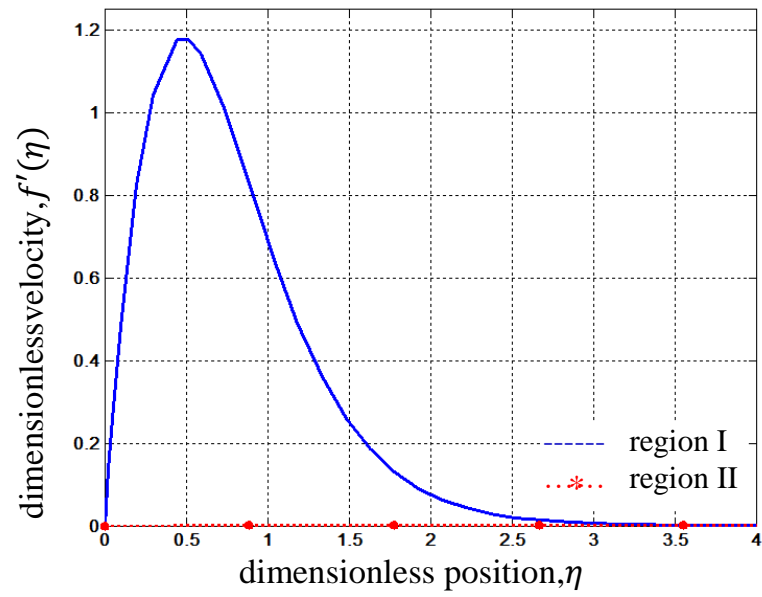

ty profile of the second region was banished and the temperature profile of the second region is greater than the first region, so the results can be explained the disappearance of the second boundary layer in the visualization photographs. Therefore, the results presented are satisfied asymptotically and support the validity of the suggested physical model.

Fig. 7, a, b depict that with the increasing Grashof number, velocity and temperature profiles increase in the first region and a decrease in the second region, on the other hand it appears a critical value of Grashof number which is depended from angle inclination and which reduce the second region instable, this is due to the transformation to the third region (plume).

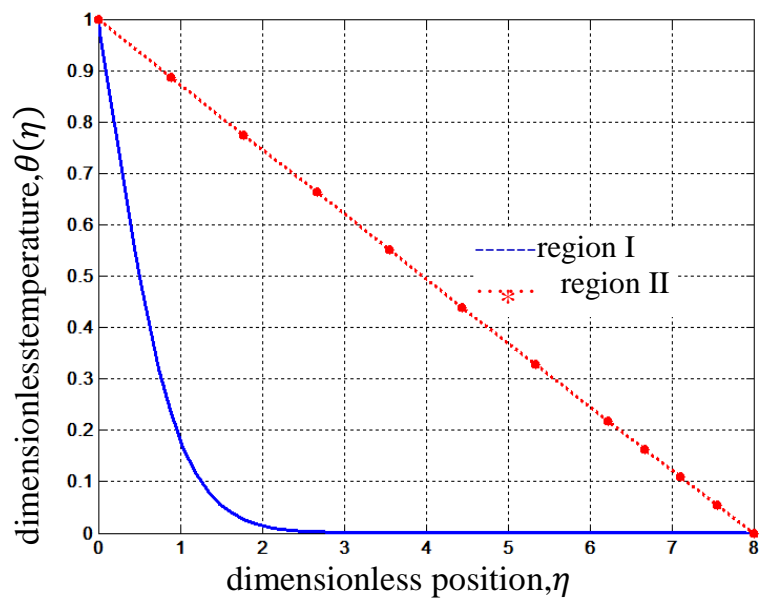

b

Fig. 6 Velocity a) and temperature b) distributions against $\eta$ for angle value $\left(\varphi=76.86^{\circ}\right), \operatorname{Pr}=0.72, G r=0.5^{*} 10^{3}$ and $M=0$

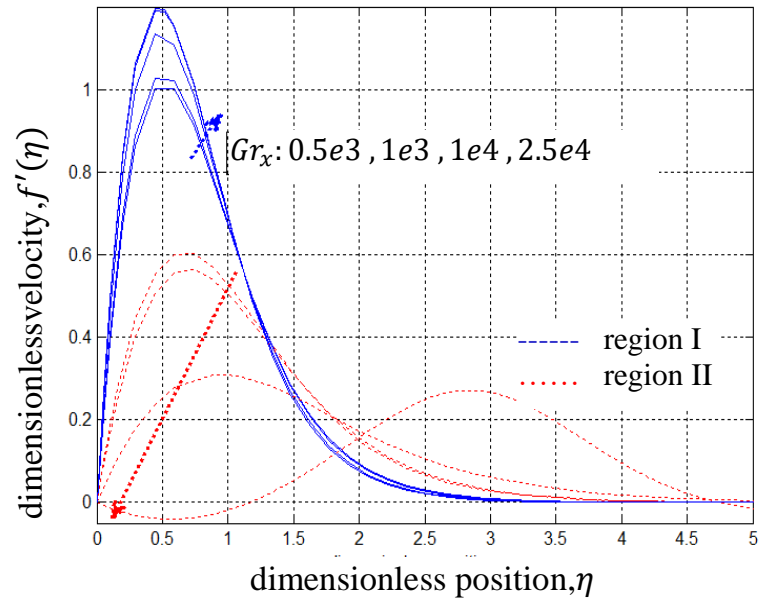

a

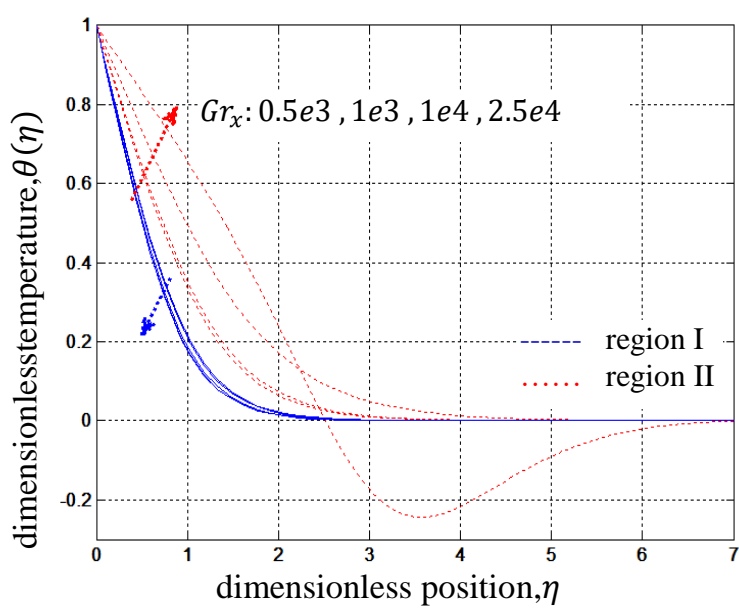

$b$

Fig.7 Velocity a) and temperature b) distributions against $\eta$ for inclined plate $\left(\varphi=60^{\circ}\right)$ for different values of Grashof number, $\operatorname{Pr}=0.72, M=0$

Beside to semi-analytical investigation of Lewandowski [20], which study just the case of $\operatorname{Pr}=1$, the present research examined for various Prandtl number, velocity and temperature profiles are plotted in Figs. 8, a, b. The velocity of air $(\operatorname{Pr}=0.72)$ is always greater than the velocity of water $(\operatorname{Pr}=7)$ in the same value of parameters for both regions I and II. Fig. 8, b shows that the effect of Prandtl number is very important in the temperature profiles. The thermal boundary layer thickness decreases with the increasing of the Prandtl number in the two regions, as it is known in classical studies.
From Fig. 9, a, b it is clear that magnetic field parameter $M$ has a retarding effect on the velocity of the fluid. It is due to the fact that there exists an opposite force to the flow called Lorentz force and which results in thinning of the boundary layer thickness, and hence induces an increase in the absolute value of the velocity gradient at the surface, so the velocity profiles decreases, while the temperature profiles increases owing to the increase of magnetic field $M$.

The influence of Eckert number $E_{c}$ over dimensionless velocity and temperature profiles are shown in 
Figs.10, a, b. It is observed that an increase in Eckert number enhances the temperature because the heat energy is stored in the fluid due to the frictional heating, hence, a

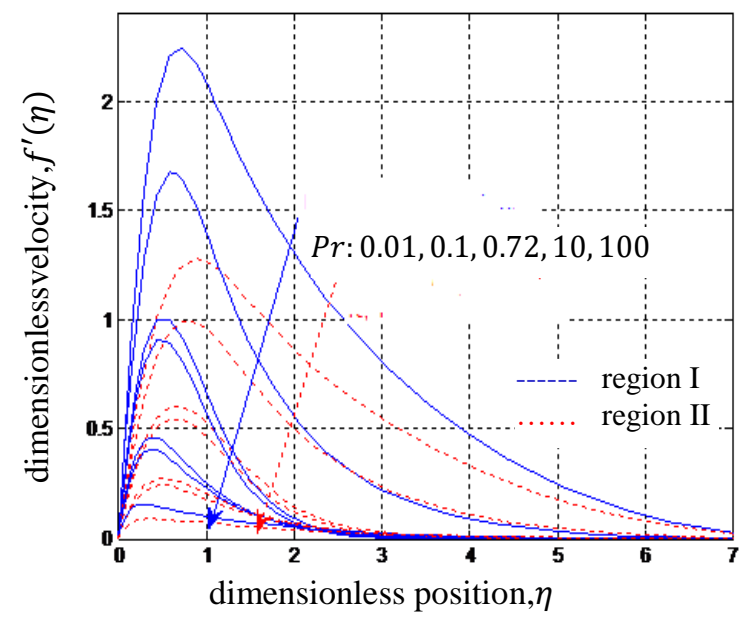

a decrease of the velocity distribution in the both flow regions.

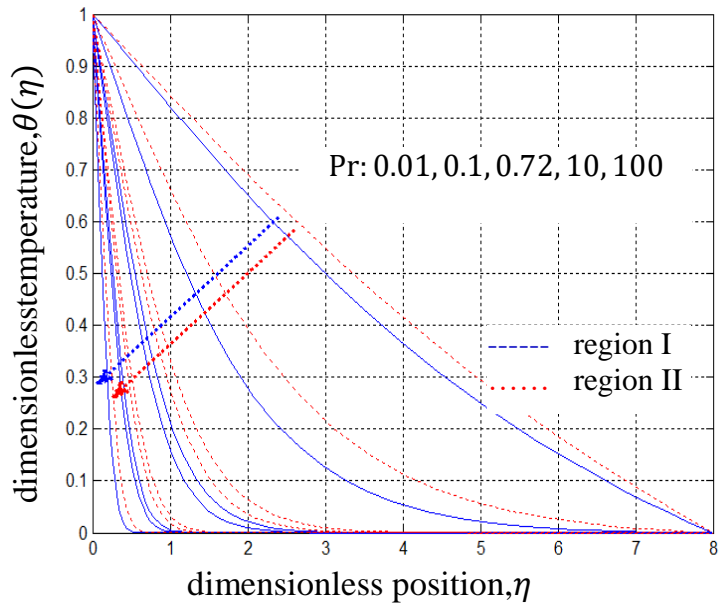

$\mathrm{b}$

Fig.8 Velocity a) and temperature b) distributions against $\eta$ for inclined plate $\left(\varphi=60^{\circ}\right)$ for different values of Prandtl number, $G r=0.5^{*} 10^{3}, M=0$

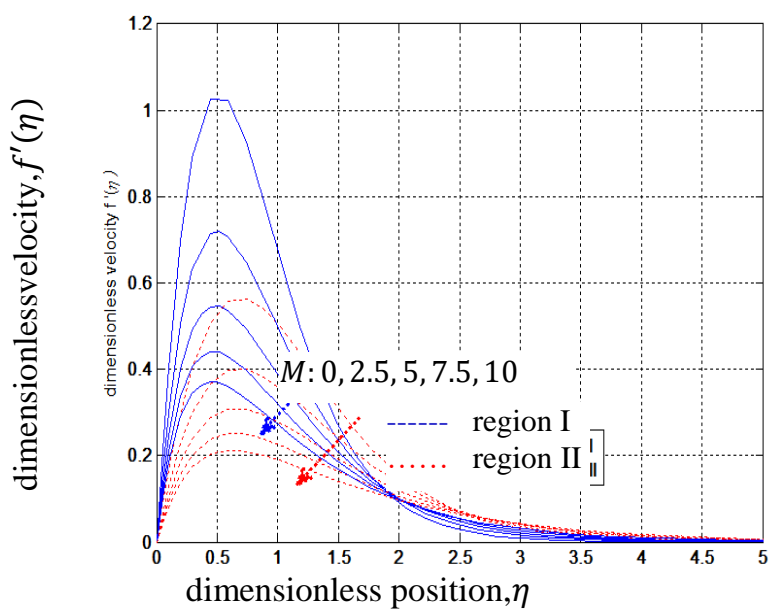

a

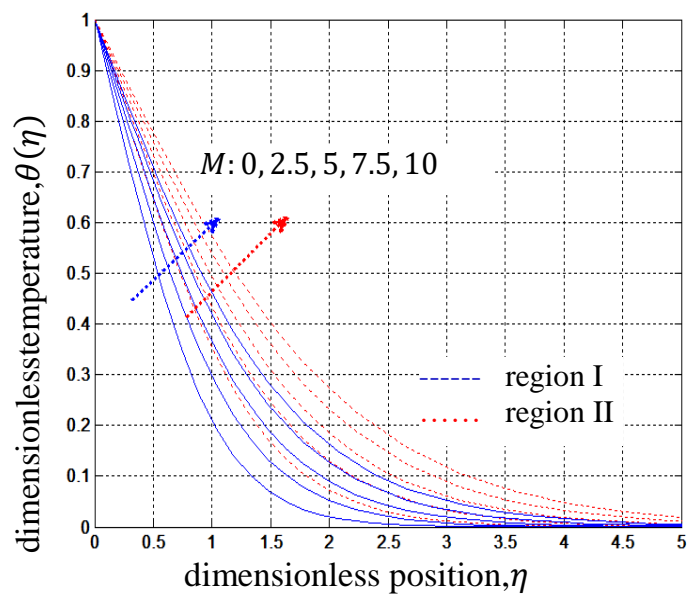

b

Fig. 9 Velocity a) and temperature b) distributions against $\eta$ for inclined plate $\left(\varphi=60^{\circ}\right)$ for different values of magnetic field parameter, $G r=0.5^{*} 10^{3}, \operatorname{Pr}=0.72$ and $E_{c}=0$.

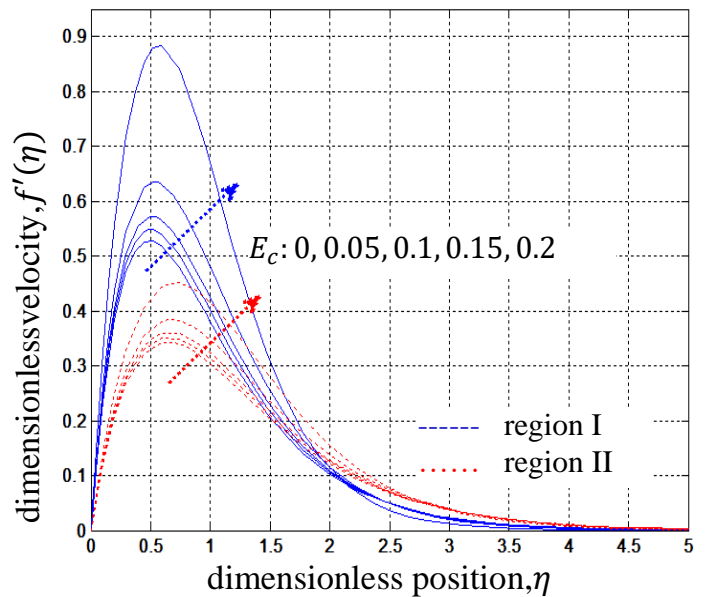

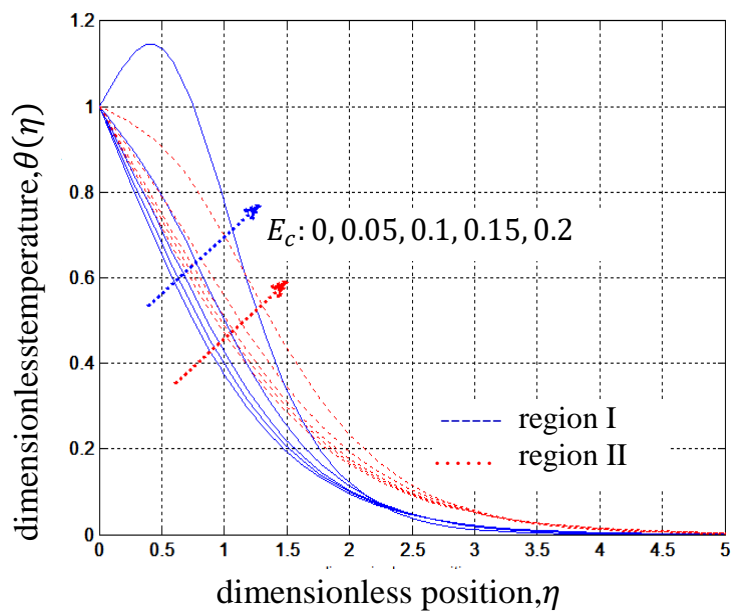

$\mathrm{b}$

Fig. 10 Velocity a) and temperature b) distributions against $\eta$ for inclined plate $\left(\varphi=60^{\circ}\right)$ for different values of Eckert number, $\mathrm{Gr}=0.5^{*} 10^{3}, \operatorname{Pr}=0.72$ and $\mathrm{M}=5$ 
The relationship of the local Nusselt number $N u_{x}$ as a function of local Rayleigh number $R a_{x}$ and the global Nusselt number $N u_{d}$ with the global Rayleigh number $R a_{d}$ are depicted, respectively, in Figs. 11 and 12 for the both region I and II.

From Fig. 11, the local Nusselt calculated for the two regions with the formula suggested by Lewandowski [20] and based on the quasi-analytical solution is found in divergence with the present results. In our opinion, some simplifying assumptions for the quasi-analytical solution are not reasonable. The presence of the magnetic field can be seen as a tool to regulate the velocity, but with a loss of the convective heat exchange, as shown in Fig. 12.

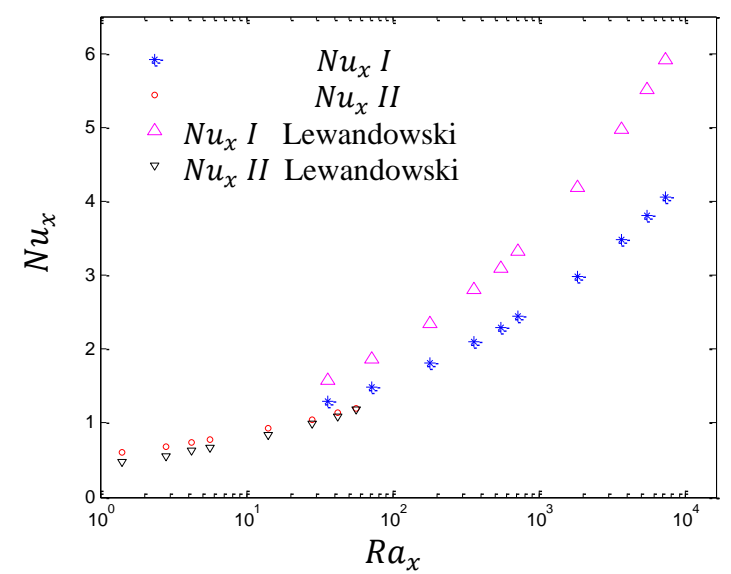

Fig. 11 Local Nusselt against local Rayleigh for inclined plate $\left(\varphi=60^{\circ}\right), M=0$

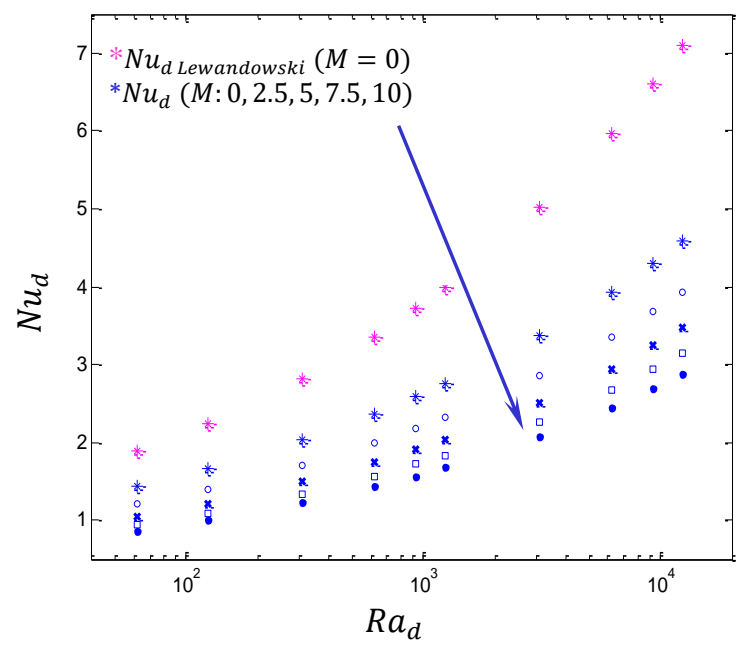

Fig. 12 Global Nusselt against global Rayleigh for inclined plate $\left(\varphi=60^{\circ}\right)$ for different $M$

\section{Conclusions}

The present study involved on a numerical approach on MHD natural convection boundary layer flow from a finite isothermal flat plate of arbitrary inclined surface. The governing partial differential equations were transformed into a system of ordinary differential equations using suitable similarity transformations. The resulting equations were then solved and the results obtained can be summarized as follows:

- An excellent and physically agreement was observed between our results and those obtained using technical visualization giving confidence to the suggested model.
- With an increased inclination angle $\varphi$, the maximal velocity in the first region grows while in the second region decrease more and more rapidly until the disappearance. This tendency is inverted for the temperature, but the profile remains in all cases. This behavior is valid also for the Grashof number.

- It appears a critical value of Grashof number which is depended from angle inclination which reduce the second region instable, owing the transformation to the plume.

- All the parameters, $M, E c$ as well as $P r$ have a profound effect on the velocity and temperature profiles in the both regions I and II.

- This present procedure seems to produce better estimation for local or global convective heat transfer coefficient involving plate with finite dimensions.

\section{Acknowledgments}

This work was supported in entire part by the $\mathrm{Bi}$ omaterials and transport phenomena laboratory agreement $\mathrm{N}^{\circ} 303$ 03-12-2003, at university of Medea. M. Bouksani and M.N. Bouaziz acknowledge the financial support provided by DG-RSDT of Algeria.

\section{References}

1. Fujii, T.; Imura, H. 1972. Natural convection heat transfer from a plate with arbitrary inclination, International Journal of Heat Mass Transfer 15: 755-764. http://dx.doi.org/10.1016/0017-9310(72)90118-4.

2. Kierkus, W.1968. An analysis of laminar free convection flow and heat transfer about an inclined isothermal plate, International Journal of Heat and Mass Transfer 11: 241-253. http://dx.doi.org/10.1016/0017-9310(68)90153-1.

3. Umemura, A.; Nam, S.; Law, C.K. 1990. Natural convection boundary layer flow over a heated plate with arbitrary inclination, Journal of Fluid Mechanics 219: 571-584. http://dx.doi.org/10.1017/S0022112090003081.

4. Hossain, M.A.; Pop, I.; Ahmad, M. 1996. MHD free convection flow from an isothermal plate inclined at a small angle to the horizontal, Journal Theoretical and Applied Fluid Mechanics 1: 194-207. http://citeseerx.ist.psu.edu/viewdoc/download?doi=10. 1.1.476.9547.

5. Anghel, M.; Hossain, M.A.; Zeb, S.; Pop, I. 2001. Combined heat and Mass Transfer by free Convection Past an Inclined flat Plate, International Journal Applied Mechanics and Engineering 2: 473-497. https://www.infona.pl/resource/bwmeta1.element.bazte ch-article-BPZ2-0009-0025

6. Yu, W.S.; Lin, H.T. 1988. Free convection heat transfer from an isothermal plate with arbitrary inclination, Wärme-und Stoffübertragung 23(4): 203-211. http://link.springer.com/article/10.1007/BF01807322.

7. Lin, H.T. ; Yu, W.S.; Yang, S L. 1989. Free convection on an arbitrary inclined plate with uniform surface heat flux, Wärme-und Stoffübertragung 24: 183-190. http://link.springer.com/article/10.1007/BF01590018

8. Pera, L.; Gebhart, B. 1973. Natural convection boundary layer flow over horizontal and slightly inclined surfaces, International Journal Heat Mass Transfer 16: 1131-1146. 
http://dx.doi.org/10.1016/0017-9310(73)90126-9.

9. Ghosh, S.K.; Bhattacharjee, P.K. 2000. Magnetohydrodynamic convective flow in a rotating channel, Archives of Mechanics 52(2): 330-318. http://am.ippt.pan.pl/am/article/view/14/0.

10. Ghosh, S.K.; Nandi, D.K. 2000. Magnetohydrodynamic fully developed combined convection flow between vertical plates heated asymmetrically, Journal of Technical Physics 41(2): 173-185.

https://www.infona.pl/resource/bwmeta1.element.bazte ch-article-BAT2-0001-0853.

11. Ghosh, S.K.; Pop, I.; Nandi, D.K. 2002. MHD fully developed mixed convection flow with asymmetric heating of the wall, International Journal of Applied Mechanics and Engineering 7(4): 1211-1228.

https://www.infona.pl/resource/bwmeta1.element.bazte ch-article-BPZ2-0001-0064.

12. Alam, M.S.; Rahman, M.M.; Sattar, M.A 2006. MHD free convective heat and mass transfer flow past an inclined surface with heat generation, Thammasat International Journal of Sciences and Technology 11(4): 1-8.

http://203.131.219.173/journal/0111/11_4_oct_dec_20 06/02PAGE1_PAGE8.pdf.

13. Pandya, N.; Shukla, A.K. 2013. Soret-Dufour and radiation effects on unsteady MHD flow past an impulsively started inclined porous plate with variable temperature and mass diffusion, International Journal of Mathematics and Scientific Computing 3(2): 41-48. http://ijma.info/index.php/ijma/article/view/4429.

14. Chen, C.H. 2004. Heat and mass transfer in MHD flow by natural convection from a permeable inclined surface with variable wall temperature and concentration, ActaMechanica 172:219-235.

http://link.springer.com/article/10.1007/s00707-0040155-5.

15. Das, S.; Sarkar, B.C.; Jana, R.N. 2013. Entropy Generation in MHD Free Convective Boundary Layer Flow Past an Inclined Flat Plate Embedded in a Porous Medium with Hall Currents, International Journal of Computers Applications 84(9): 36-46. http://dx.doi.org/10.5120/14608-2875.

16. Hazarika, S.; Hazarika, G.C. 2015. Effects of variable viscosity and thermal conductivity on MHD free convection and mass transfer flow over an inclined vertical surface in a porous medium with heat generation, The International Journal of Engineering and Science 4: 20-27. http://adsabs.harvard.edu/abs/2015IJCA..122h..29C.

17. Shrama, P.R.; Singh, G. 2010. Steady MHD natural convection flow with variable electrical conductivity and heat generation along an isothermal vertical plate, Tamkang Journal of Science and Engineering 13(3): 235-242.

http://www2.tku.edu.tw/ tkjse/13-3/02-M9707.pdf.

18. Masthanrao, S.; Balamurugan, K.S.; Varma, S.V. K. 2013. Chemical reaction effects on MHD free convection flow through a porous medium bounded by an inclined surface, International Journal of Mathematics and Computer Applications Research 3: 13-22.

http://www.academia.edu/download/31645217/2._CHE MICAL_REACTION_EFFECTS_-_-full.pdf

19. Lewandowski, W.M.; Radziemska, E. 2001. Heat transfer by free convection from an isothermal vertical round plate in unlimited space, Applied Energy 68: 187-201.

http://dx.doi.org/10.1016/S0306-2619(00)00053-2.

20. Lewandowski, W.M. 1991. Natural convection heat transfer from plates of finite dimension, International Journal of Heat and Mass Transfer 34: 875-885. http://dx.doi.org/10.1016/0017-9310(91)90133-Y.

21. Ghosh, S.K.; Pop, I. 2005. A new approach on MHD natural convection boundary layer flow past a flat plate of finite dimensions, International Journal of Heat Mass Transfer 42: 587-595. http://dx.doi.org/10.1007/s00231-005-0047-9.

22. Schmidt, E.; Beckmann, W. 1930. Das Temperatur und Geschwindigkeitsfeldvoreiner Warmeabgebenden Senkrechten Plattebeinaturlicher Konvektion Technische Mechanik und Thermodynamik 1: 341-349. http://link.springer.com/article/10.1007/BF02660553.

23. Kimura, F.; Yoshioka, T.; Kitamura, K.; Yamaguchi, M.; Asami, T. 2002. Fluid flow and heat transfer of natural convection at a slightly inclined, upwardfacing heated plate, Heat Transfer, Asian Research 31(5): 362-375. http://dx.doi.org/10.1002/htj.10036.

24. Chen, T.S.; Tien, H.C.; Armaly, B.F. 1986. Natural convection on horizontal, inclined, and vertical plates with variable surface temperature or heat flux, International Journal of Heat and Mass Transfer 29(10): 14651478.

http://dx.doi.org/10.1016/0017-9310(86)90061-X.

\section{Bouksani, M. N. Bouaziz}

\section{COMPUTATION OF CONVECTIVE HEAT TRANSFER COEFFICIENT FOR FINITE INCLINED AND ISOTHERMAL PLATE}

S u m m a r y

In order to compute the convective heat transfer coefficient, the present study develops a new technical approach of the constitutive equations of the fluid, based on a realistic physical model of heat transfer for an inclined and an isothermal plate with finite dimensions. Two separate regions with different fluid motions are distinguished. Using suitable transformations of differential equations, the similarity ordinary differential equations were obtained and then solved by an appropriate and simple finite difference method. The analysis of numerical results for some special cases of inclination with visualization photographs is found to be in very good agreement. Numerical results for the dimensionless velocity and temperature profiles are obtained and reported graphically for various values of the parameters entering into the problem. It has observed that Lorenz forces are suitable to control the velocity. Discrepancy between the quasi-analytical formula and the present numerical results are recorded for the Nusselt number and for both the two regions.

Keywords: Inclined finite plate, physical model, MHD, natural convection, two regions, boundary layer.

Received April 17, 2016 Accepted August 04, 2017 